IDEA - Studia nad strukturą i rozwojem pojęć filozoficznych XXVIII/1

Białystok 2016

\author{
MARISELA LÓPEZ ZALDÍVAR \\ (Mexico City, Meksyk)

\section{THE INFRASPACE. (IL)LEGAL AND A-LEGAL SPACES AS PRODUCERS OF SUBJECTIVITY}

\title{
Introduction
}

Foucault argued that power can create/set/legitimize/legalize discourses that function as the parameters of the (un)desirable in society. Those discourses can create subjectivity -by the discipline of the bodies- and spaces -by establishing an order-.$^{1}$ On one hand, Foucault proposed that space/place produce subjectivity. ${ }^{2}$ On the other hand, Foucault proposed that spaces/places are social constructions organized/created by the power and relationships emplaced somewhere. ${ }^{3}$

${ }^{1}$ Cf. Michel Foucault, Discipline and punish: the birth of the prison, trans. Alan Sheridan, New York: Vintage Books, 1979. M. Foucault, “Of other spaces”, trans. Jay Miskowiec, Diacritics 16, no. 1, 1986, 22-27. [1st English translation]. Same, "Of Other Spaces: Utopias and Heterotopias". In Rethinking Architecture: A Reader in Cultural Theory. Trans. Lotus, ed. N. Leach, London: Routledge, 1997. [2nd English translation]; Same, "Espacios Otros", trans. Marie Lourdes, Versión. Estudios de Comunicación y Politica no. 9, 1999. [Spanish translation]. Same, The Order of Things: An Archaeology of the Human Sciences, London; New York: Routledge, 2002.

${ }^{2}$ Ibid.

${ }^{3}$ Cf. The conference Foucault "Of Other Spaces: Utopias and Heterotopias" [2nd English translation] uses the concept of "arrangement". On the other hand, "Of other spaces" [1st English translation] uses the concept of "emplacement". Even though both conferences are the same one, 
Foucault analyzed the subjectivity produced by different spaces/places as the hospital, the school and the prison. ${ }^{4}$ Although all of the previous places are different, I must emphasize they share the main feature of being legal. Then, inspired by Foucault's work and the 'spatial turn', this research enquires if subjectivities can be produced by other spaces besides the legal ones. That will be answered by analyzing the existence of other spaces that can complement or be the counterpart of the legal space. I put forward the following hypothesis: the legal spaces/places are not a synonym of 'everywhere'. The legal discourse about space and the spatial analysis of the legal spaces hinder the possibility of considering the existence of an illegal/a-legal space. As a conclusion it will be exposed how the production of subjectivity can be produced in what I will name as the infraspace.

In order to contribute to the law and space studies, my research is an attempt to go beyond the space-place legal discursive categories because if not, it would turn into an analysis of the legal spaces/places in the law's perspective. This emphasis to avoid the legal epistemological discursive cage is an invitation to focus on the a-legal space and its normative potential.

\section{The legal space-place and its limitations}

A link between the legal and the spatial has always existed since the creation of law because objects and subjects had to be located somewhere in order to define which law was meant to be applied where. The aim of this statement is

both use different concepts to refer to the third stage in which space is understood. It is worth to mention that "arrangement" refers more to social networks while "emplacement" refers to the position of them somewhere.

${ }^{4}$ Art. Cit. M. Foucault, Discipline and punish: the birth of the prison; Same, The Birth of the Clinic, An archaeology of Medical Perception, New York, Pantheon, 1973; T. Besley, T. and M. Peters, Subjectivity and Truth: Foucault, Education and the Culture of Self, New York, 2007, 79.

${ }^{5}$ Andreas Philippopoulos-Mihalopoulos, Law's Spatial Turn: Geography, Justice and a Certain Fear of Space in Law, "Culture and the Humanities" 7, no. 2, 2011, 187-202. Nicholas Blomley, et al. The Expanding Spaces of Law: A Timely Legal Geography, California: Stanford University Press, 2014. 
not to introduce a historical compilation about law-geography interaction to expose the discussions in which the space-law link has been (un)constructed. Instead, that statement is to consider the space-law link as a fact and better wonder about the perspectives that have analyzed it as well as the possible implications of it.

\section{The legal perspective about space-place}

I suggest the law has a pretension to dominate the space due to the law is the one that sets the parameters to define places. The law defines the places but places cannot define law in the same way. The places become subjected to the law by the effect of the following double process. Firstly, the law uses legal jargon as a tool to create places-spaces by establishing definitions, delimitations and borders. Secondly, the law establishes which terms will rule in the previously created categories. For example, the sea and the ocean are 'natural spaces' that after the discursive power of law have become a place divided into 'archipelagic waters', 'territorial sea', 'contiguous zone', 'exclusive economic zone' and 'high seas' or 'international waters'. ${ }^{6}$ Also, the law determines which kind of actions or individuals will be (un)tolerated in each of those 'zones' by defining access and restriction policies.

The law regulates place-space-land by using its own conceptual framing based on the juridical and supported by the geographical and the economical while influenced by the political. Some examples of this regulation are the following ones: jurisdiction, borders, public/private spaces, property, maritime zone, nudist beaches, islands, commercial areas, residential areas, military restricted areas, international areas -embassies, airports- or sui generis places like the Vatican City(state), Palestine or the Turkish republic of Northern Cyprus.

The previous idea about the legal framing as a tool to create places-spaces implies the following double process. In general, I will summarize those parameters in a binomial category inspired on the geographical and the economical. On one hand, the spaces-places are defined by economic terms. For example,

\footnotetext{
${ }^{6}$ Cf. United Nations, Convention on the Law of the Sea, 1982
} 
the legal parameters about sale and ownership that define place-space in terms of what kind of places can(not) be sell nor exploited and who can own what and access where. On the other hand, the places are defined by geography and politics, like the (inter)national private law which defines place-space in (post) sovereignty terms. For example, geography and politics can define the following: (a) whether a location is a state or an island or 'kind of a somewhere' with political autonomous aspirations; (b) the spaces-places of war where humanitarian law will apply; (c) where a state can execute jurisdiction. Also, 'the political' is related with the binomial category exposed above by contributing with the public, private and intimate place-space distinction.

Nevertheless, if the normative ideals exposed above about law and placesspaces are not working on real life, then distortions of power and norms happen. Particularly, when the law has a lack of spatial control in the public space, the informal norms override the formal norms. Then, an empowerment over legality happens and the consequence is considered as a sort of rebellion or dysfunction. Consequently, those conditions allow the possibility to name a place as 'lawless' and justify state intervention. ${ }^{7}$ Are those 'lawless' places a legal fault or are they places with a different normative order?

The previous exposition has been merely a general 'cartography of legal places-spaces' in order to picture a legal analysis of space-place perspective. That perspective considers the coexistence of (in)formal norms with legal norms among legal spaces-places. That perspective considers the spaces-places as the ones recognized by law also considers spaces beyond the legal as a fault that must be fixed, as the lawless place explained above. The purpose to set that 'cartography' is not to follow it, complement it or analyze it but to avoid it.

\section{The spatial perspective of the legal places-spaces}

The so called 'spatial turn' of the law has been elaborating other ways to understand space 'outside' of codes, laws and norms framing. A great collabora-

${ }^{7}$ Cf. Julieta Lemaitre."Constitution or barbarism. How to rethink law in "lawless" spaces?" in Law and Society in Latin America A new map, ed. Cesar Rodriguez-Garavito, UK: Routledge, 2015, 47-48. 
tion about this perspective is the interdisciplinary approach made by Andreas Philippopoulos-Mihalopoulos to highlight that several attempts to study the 'law-space' duo have had a lack of spatialization. ${ }^{8}$ His work assumes the challenge of spatializing law, like a philosophical-geographical analysis of the legal.

Andreas Philippopoulos-Mihalopoulos proposes the following. Everything is a space so there is not such as "outside" of it, also space and law are a tautology and those together integrate the 'lawscape' which is a spatiolegal continuum that affects bodies at the same time is being affected by them. The bodies can withdrawal from the lawscape into 'atmospheres' which are like a simulated disruption of the legal continuum because are spaces in which law might look like intensified or absent but it is still there. ${ }^{9}$

The 'law spatial turn' is an excellent proposal to think beyond the legal epistemological way not only because it includes both (un)written norms but also due to the fact that it uses "geographilosophical" framing to explain law. For example, the concepts of spatial justice, atmosphere and lawscape. However, besides the interdisciplinary perspective added into the spatial approach, it has not been easy to leave aside the space legal framing done by codes, laws and norms. ${ }^{10}$

The above "geographicalegal" narrative is compatible with the legal narrative and this is the reason about why it is a valid theory to explain law's dynamics. "Law without space or space without law is an epistemological simplification or even worse, a disciplinary violence. ${ }^{11}$ Then, both narratives complement each other because intrinsically they share the same legal discourse even though the spatial perspective might be critical towards law. I mean, the spatial turn has analyzed the legal spaces.

${ }^{8}$ Cf. Andreas Philippopoulos-Mihalopoulos, Spatial Justice: Body, Lawscape, Atmosphere, UK: Routledge, 2015.

${ }^{9}$ Cf. Art. Cit. A. Philippopoulos-Mihalopoulos, Spatial Justice: Body, Lawscape, Atmosphere, 4.

${ }^{10}$ See an example of the work that leave behind the legal framing of (il)legality in Hans Lindahl, Fault Lines of Globalization: Legal Order and the Politics of A-Legality, Oxford: Oxford University Press, 2013; Schaap, Andrew et al. Critical Exchange on 'Fault Lines of Globalization in “Contemporary Political Theory", 2015.

${ }^{11}$ Art. Cit. A. Philippopoulos-Mihalopoulos, Spatial Justice: Body, Lawscape, Atmosphere, 52. 


\section{Infraspace: the (il)legal-a-legal space and its contribution}

Based on the previously exposed about the legal perspective of space and the spatial perspective of the legal spaces -spatiolegal-, it is possible to notice that both postures are influenced/based by the legal discourse of space-place. On one hand, the legal perspective considers the places that do not match with its categories as "lawless" places, as insurrection spaces in order to justify the state intervention to reestablish the legal order to put that space back into its legal category. Then places can be classified as anomy (lawless) or by a binary category: (il)legal. On the other hand, the spatiolegal perspective analyzes the regulation/function of the legality among space/place. It considers that law is everywhere being dynamic by the spatial justice and being exposed in different scales by atmospheres but everywhere anyway. This text agrees with the latter perspective but with the following twist: law is not everywhere but regulation it is.

The creation of a posture by exchanging "the legal" or "the law" by "regulation" might seem odd but it is important to avoid identifying the noun -lawwith an action -regulate-. While the law is necessarily a legal regulation, the action of regulating society can be done as well by the legal, a-legal, illegal, social, technical norms, etc. Then considering that law is everywhere would be accepting the role of the space-place as a secondary element that (a) locates law, (b) is embedded with law or (c) within the law, instead of considering the space as a producer of subjectivity. The regulation can reach where the law cannot. The distinction is worth it because it opens the possibility to think about an "everywhere" integrated by the legal space, and the a-legal space. Subjectivity produced by different spatial terms and not only by the legal ones.

The law is not the sovereign of the regulation; it might be the official and the mainstream way of regulating the social world but definitely not the only one or the main one. The social agents create regulation and spaces create regulation by the bounce of its effects. Remaining in the legal or spatialized perspective of law-space-place implies intrinsically the idea about law's domination towards spaces-places. That implies to ignore the possibility of considering the 
regulation as the counterpart of law. A counterpart that cannot be found only inside the dichotomy or the (il)legal but into the political or the a-legal. If according to Foucault the spaces emerge simultaneously with the order set by discourses ${ }^{12}$, then I suggest exploring the spatial possibilities of other normative discourses.

\section{Conceptualizing the Infraspace}

Lefebvre's work proposed a trialectic in order to explain how the production of the space was done. While the dialectic has necessarily two elements that end up in a synthesis, the trialectic has three elements in contradiction that never reach a synthesis but remain in constant interaction. ${ }^{13}$ Those three elements are the categories used by Lefebvre to classify the space. First, representational or the lived space, which does not necessarily have consistent or coherent rules due to is the space as the way users experience it. Second, the spatial practices or the perceived space, as its name says it is based on the people's spatial perception. Third, the representations of space or the conceived space is the discursively constructed space by professionals. ${ }^{14}$

According to Lefebvre, the space is socially produced and non-static due to time intervention. ${ }^{15}$ Based on that, it is tempting to wonder if the space constantly changes then which is the parameter used to classify space into 'spatial practices', 'representations of space' and 'space representations'? How is it possible to classify the space complexity in three strict categories without being sur-

\footnotetext{
12 Supra 1.

${ }^{13}$ Cf. Henri Lefebvre, The Production of Space. Trans. N. Donald Nicholson-Smith, Malden,
} MA Oxford: Blackwell Publishing, 1991, 33; Christian Schmid, "Henri Lefebvre's theory of the production of space: towards a three-dimensional dialectic", in Space, Difference, Everyday Life. Reading Henri Lefebvre, ed. Stefan Kipfer et al. UK/NY: Routledge, 2008, 36, 39-40; E. Stuart. "There is a Politics of Space because Space is Political. Henri Lefebvre and the Production of Space”. Radical Philosophy Review 10, no. 2, 2007, 110.

${ }^{14}$ Art. Cit. H. Lefebvre

${ }^{15}$ Cf. Jeremy W. Crampton, "Foucault and Space, Territory, Geography", in A Companion to Foucault, eds. Falzon, C., O'Leary, T., Sawicki, J., Oxford: Wiley-Blackwell Publishing, 2012; art. Cit. M. Foucault, "Of other spaces"[1st translation]. 
passed by time? To answer that I will suggest to focus in explaining what allows distinguishing each space from other space and their overlapping possibilities.

Visually, the Lefebvre's triad might be represented as a kind of triangle in which each space is the edge/corner and those together produce the social space. If so, each space exists without a parameter to distinguish what makes it not to be like the other. For example, there is no way to know what defines the spatial practices as such, because they define themselves. It can be said that spatial practices are the result of the physical or the perception, etc. Nevertheless, that would be just describing the characteristics of 'spatial practices' which is not the same as knowing why the 'spatial practices' are the 'spatial practices'. If each space is defined by itself then the way to identify their differences would end up in something as incoherent as 'the physical space is physical because it is not mental and not experienced', 'the mental is the one that is neither physical nor experienced' and so on.

A space must not be conceptualized through the contrast of its opposite because that would be just creating antonyms like mental-physical instead of creating concepts. I suggest to conceptualize a space by means of its differences, then it must be used a parameter to distinguish between 'a space and the other ${ }^{16}$. If the aim is distinguishing other spaces than the legal, then the parameter should be the discourses from which a space emerges. Based on Lefebvre's categories, the legal space is the conceived space but also the lived and the perceived spaces should be considered. That parameter would be the fundament to explain why the spatial categories have been done in such way. The latter responds why 'the spatial practices' are different towards other spaces. Based on the previous, this research suggests "the lived/experienced space" as the parameter that sets the distinction between the perceived/physical and the conceived/mental spaces.

Visually, if the 'physical space' is on one side and the 'mental space' in the opposite one, then the lived/experienced is the margin in the middle of both. If it were a limit instead of a margin, that limit could restrict the spaces' area by

\footnotetext{
${ }^{16}$ Cf. Jacques, Derrida. Margins of Philosophy, trans. Alan Bass, Chicago: Chicago University Press, 1982.
} 
classifying it through antonyms (as it was aforementioned). Instead, a margin is just 'there'; it cannot be transcended/ controlled/shifted or dominated. The margin works as the parameter to differentiate between 'the physical' and 'the mental' while at the same time is the 'non-place place' where is located the conjunction of both. The margin complements the mental with the physical and backwards; it allows thinking about what is 'the mental' part based on 'the physical' and what is 'the physical' part based on 'the mental. ${ }^{17}$ Consequently, 'the experienced' is based on 'the physical', 'the mental' or on both.

The previous paragraph does not modify Lefebvre's theory because his concepts are applied with the same content he provided for them. In fact, my interpretation is a way to reinterpret Lefebvre's work while keeping his proposal expressed through the trialectic. ${ }^{18} \mathrm{My}$ interpretation is based on Derrida's thesis exposed in The Margins of Philosophy in The Tympanum. ${ }^{19}$

A tympanum is not inside but also not outside; it is an aporia; it is a 'nonplace place' and that is why it is so relevant. The tympanum is the place from where it can be defined what the inside and the outside are; it is the somewhere in which 'the outside has an inside' and where the 'inside has an outside'. The tympanum, suspends the limit that establishes borders between 'inside-outside'. The tympanum, as a 'non-place' place, allows conceptualizing 'the outside of the inside' and 'the inside of the outside': the place from where it is possible to define both. ${ }^{20}$ That is why the aporia works to expose the possibility of new complex spatial categories. Then, as it can be inferred from the previous, my research argues that Lefebvre's concepts are useful to expose 'the margins of the space' and that Lefebvre's 'spaces of representation' can work as the Derrida's tympanum. Consequently, it is possible to conceive other spaces with their own normative content, able to produce subjectivity and that are not only legal spaces.

\footnotetext{
${ }^{17}$ Supra 5-6.

${ }^{18}$ Supra 5.

${ }^{19}$ Art. Cit. Derrida. "Tympanum” in Margins of Philosophy, (see note 16).

${ }^{20} \mathrm{Ibid}$.
} 
My proposal is about thinking the space beyond the legal terms but still space related with social regulation. Then, it will show the spaces that law and its two-dimensional categories of legal-illegal antonyms cannot conceptualize. Those spaces, as the Derrida's margin, are 'non-place places' that cannot be controlled by the law but they just exist 'somewhere' in between the (il)legality. I will name those spaces as infraspaces, they exist and also regulate society but are unable to be located and the law cannot absorb them nor control them. The infraspaces are the margin that allows considering the possibility of the illegality in the a-legality and also the legality in the a-legality.

The infraspace is not legal because if so, the law and its pretension of regulate everything somehow would have include it already. The infraspace is not entirely illegal because if so, it would be just a crime. The infraspace is the margin of the legal spaces (conceived) and the geographical spaces (perceived); it is the margin in which the a-legal-(il)legal meet each other; it is the parameter that sets the difference among the (il)legal space.

Furthermore, the infraspace was not named as "alternative space" or "unofficial" in order to stop creating definitions subordinated to the hegemonic legal discourse of space. Also it has been named as infraspace to focus in the potential it has to create and execute non-legal regulation (social, illegal, a-legal, technical) in a parallel way to the legal. In metaphorical terms, the legal space is like the visible light because it is the first that can be seen but it is not the only one among the light spectrum. There are also other kinds of light, like the infrared which exists at the same time and it is there as well even though it cannot be seen at first sight, like the infraspace.

\section{The production of subjectivity in infraspaces}

It has been said that Foucault's text of The Order of Things ${ }^{21}$ implies a distinction about the same and the other in order to expose how it has been set the parameter of the considered as normal and, as a consequence, what might be

\footnotetext{
${ }^{21}$ Cf. Art. Cit. M. Foucault, The Order of Things: An Archaeology of the Human Sciences.
} 
found beyond the borders of the desirable. ${ }^{22}$ That distinction matches with the official space because the places that were analyzed to create it were the clinic and the prison, which are places or spaces regulated by the legal dominium. In law, the legal terms pretend to be universal in order to guarantee "equity" and "equality" due to the law's aim is judging everyone with the same dual parameters: (in)/sane (madness), (un)healthy(sickness), homo/hetero (sexuality), innocent/guilty (criminality). Those parameters expose the (un)desirable by prescriptions of who are the same, who are the others. Those binomial categories based in knowledge and power produce the subjectivity by the control of the body. Then, the production of subjectivity in the "official places" is done by Manichaean categories of control supported by normativity embedded into law and discourses.

Based on the previous, it would be interesting to analyze in which terms the subjectivity is produced in the infraspace. So far, based on Lefebvre's spatial categories it has been exposed the infraspace as a-legal-(il)legal space. The infraspace has been conceptualized as a space that is the counterpart of the legal space. It is a space that cannot be conceptualized from the legal perspective due to it would be considered as a failure or a crime as it was exposed above in the first section. According to Foucault the spaces produce subjectivity and logically, if the infraspace is a space it should produce subjectivity as well. However it might not necessarily produce it in the same terms than legal space.

Even though the infraspace can be influenced by the legal space its influence is not strong or broad enough to set legal parameters as the ones that will determine the way in which the distinction between the same and the other is created in the infraspaces. The reason is that legal spaces are regulated by the knowledge/discourses produced by an authority or certain someone exercising the power and legalizing its normativity. Instead the infraspaces are not regulated/created by a particular authority but they are regulated by normativity that

${ }^{22}$ Cf. Chris Philo, The Same and the Other': on geographies, madness and outsiders, Loughborough University of Technology, Department of Geography, Occasional Paper 11 (1986): 1-71, doi: http://eprints.gla.ac.uk/116553/1/116553.pdf. 
emerges from the space and the experience lived in that particular location. The latter statement will be developed by the following example.

Tepito; it is the name of a legal place; it is a residential area: a neighborhood in Mexico City. In the legal perspective of space, Tepito is an informal space due to it works as commercial area. In the spatial perspective of the legal spaces, Tepito is an illegal space because is where piracy of books, movies, music and clothes is produced, stored and sold. Additionally, Tepito is the space where drugs are produced and distributed, it is the place where people goes to buy anything (piracy, animals, weapons, fake documents, etc.) it is like the black market. ${ }^{23}$ However, based in our perspective, Tepito is an infraspace.

The police have known that Tepito is a space where crime happens and it has entered there to destroy drug laboratories and confiscate piracy. The population of Tepito has been known by the popular narratives and described by the news for being brave and defend their space. They fight against any possible invasion even against any kind of authority; they are tough people and their logo is "in Tepito everything can be sold except dignity". ${ }^{24}$ Tepito is an infraspace because its characteristics of (il)legal-a-legality but also because it creates subjectivity in different terms than legal spaces. Tepito does not have written codes of the rules that organize it in the way it is ordered and there are no written rules about the behavior of the people there because Tepito is not a community but the social ensemble of residents, sellers, buyers, clients, tourists, authorities, workers, criminals. ${ }^{25}$ Even though someone is not from Tepito, only by being there it is linked to the normativity that emerges from the space. Tepito, as an infraspace, produces subjectivity by controlling the bodies in an indirect way. That means not by direct normativity imposed/established through behavior parameters but by allowing the conditions where anything can happen because is a space where the legal regulation is not everywhere but the social and the illegal or a-legal is. Therefore, the people raised in Tepito, the residents or the

${ }^{23}$ S. Quiñones, "Tepito" in True Tales From Another Mexico: The Lynch Mob, the Popsicle Kings, Chalino, and the Bronx, Albuquerque, University of New Mexico Press, 2001.

${ }^{24} \mathrm{Ibid}$.

${ }^{25}$ Ibid. 
habitants internalize practices not according to the legal but according to what allows them to survive in that space.

On one hand, the hospital, the school and the prison produce subjectivity by the exercise of dual categories supported by the normativity. ${ }^{26}$ Those categories were not created by the hospital/school/prison itself but by the subject executing the power of the discourse and claim they were needed. On the other hand, in the infraspace there is also the same and the other as categories of control and production of the subjectivity. However, there might be multiple and multidimensional spatial parameters due to the convergence or clash of place-space. The categories of control that create subjectivity in the infraspaces are based on the experience of living the mixture of the physical space, the social space and the mental space in a particular location. In the infraspace, the distinctions between the same and the other in order to create subjectivity are not legalized, codified and not necessarily written somewhere because they are produced by the space itself. Therefore infraspace produces its own normativity, its aim is not to control society but they end up doing it. As the normativity produced by the spaces is important to analyze the production of subjectivity, it will be interesting to develop in future research the kind of normativity produced by the infraspaces.

\section{Conclusions}

Finally, it has been exposed that spaces indeed work as producers of subjectivity but it is important to emphasize that not all spaces produce it in the same way or for the same aim. The legal perspective of the spaces and the spatial perspective of the legal are postures that only emphasize legal spaces as the producers of subjectivity. That focus is just about the legal spaces and due to that, it does not consider any other space; as if the legal spaces were a synonym of everywhere.

\footnotetext{
${ }^{26}$ Art. Cit. M. Foucault, Discipline and punish: the birth of the prison; Same, The Birth of the Clinic, An Archaeology of Medical Perception; T. Besley.
} 
The insistence about going beyond the framing legal discourse about spaces allows to not limiting the spatial categories to just the ones defined by law and expose the existence of other spaces with its own normativity which also have the potential to produce subjectivity. I named those spaces as infraspace and based on Lefebvre's concepts, I conceptualized the infraspace as the space of the (il)legal-a-legal that functions in a parallel way to the legal space.

The infraspace is a 'non-place place' that cannot be controlled by the law but exists 'somewhere' in between the (il)legality, it regulates society but are unable to be delimited with physical borders and the law cannot absorb it nor control them. The infraspaces are the margin that allows considering the possibility of the illegality in the a-legality and also the legality in the a-legality.

Based on that difference, on one hand, the legal spaces produce subjectivity in the Foucauldian terms of the control of the body, power and knowledge. Basically, that implies subjectivity is constructed by a Manichean parameter established by the law or the legal normativity: guilty/innocent, citizen/undocumented. The legal spaces are conceptualized by considering the influence of the politics, the political, the geographical and the economical. On the other hand, the infraspaces are defined by the people's perception or people's spatial practices then they are not necessarily delimited by geographical visible borders or strict limits. Consequently, there is not only a binomial/dual strict category that works as the parameter of the undesirable due to the categories of 'the same and the other' into the infraspace are abstract instead of established and enforced by an authority. In the infraspaces the subjectivity is produced by the space itself through multidimensional parameters that emerge from the normativity created as the consequence of the possible clash, divergence or convergence of the spaces.

The subjectivity is produced by the space and spaces emerge by the discourses which can be not only legal but a-legal and (il)legal or all of them simultaneously. Furthermore, subjectivity can be produced in a parallel way by both, the discourses allowed in the legal spaces and the a-legal-(il)legal discourses that can emerge in the infraspace. Therefore, based in a spatial analysis, the subjectivity can be produced by the legal space and by the infraspace. 


\section{Summary}

The subjectivity can be produced by the spaces; Foucault analyzed that in the hospital, the school and the prison. However, all of those places are legal. Based on that and inspired by the "spatial turn", this text questions if only legal spaces can produce subjectivity or which other spaces can produce it as well. To answer the latter, it is exposed the legal spaces cannot be considered as the equivalent to "everywhere" due to the fact that there are other spaces that exist but are not visible from the legal perspective of the space or the spatial perspective of the legal. Then, I name the spaces that exist parallel to the legal spaces as infraspace. The infraspace is an (il)legal-a-legal space that works as the counterpart of the legal space and can produce subjectivity as well but in different terms. The infraspace is proposed as the space that complements the spatial possibilities that can produce subjectivity. Therefore, subjectivity can be produced by spaces that are legal, illegal or a-legal.

Key words: Foucault, subjectivity, legal, illegal

\section{Bibliography}

T. Besley, T. and M. Peters, Subjectivity and Trutb: Foucault, Education and the Culture of Self, New York, 2007.

N. Blomley, et al. The Expanding Spaces of Law: A Timely Legal Geography, California, Stanford University Press, 2014.

J. Derrida, Margins of Philosophy, trans. Alan Bass, Chicago, Chicago University Press, 1982.

J. Derrida, "Tympanum" in Margins of Philosophy, trans. Alan Bass, Chicago, Chicago University Press, 1982.

M. Foucault, Discipline and punish: the birth of the prison, New York, Vintage Books, 1979.

M. Foucault, "Espacios Otros", trans. Marie Lourdes. Versión. Estudios de Comunicación y Politica no. 9, México, Universidad Autónoma Metropolitana, 1999, 15-26.

M. Foucault, "Of Other Spaces: Utopias and Heterotopias". In Rethinking Architecture: A Reader in Cultural Theory, trans. Lotus, ed. Neil Leach, NY/London, Routledge, 1997, 330-336.

M. Foucault, "Of other spaces", trans. Jay Miskowiec. Diacritics 16, no. 1, 1986, 22-27.

M. Foucault, The Order of Things: An Archaeology of the Human Sciences, London/New York, Routledge, 2002.

M. Foucault, The Birth of the Clinic, An archaeology of Medical Perception, New York, Pantheon, 1973.

H. Lefebvre, The Production of Space, trans. N. Donald Nicholson-Smith, Malden, MA Oxford, Blackwell Publishing, 1991. 
J. Lemaitre. "Constitution or barbarism. How to rethink law in "lawless" spaces?" in Law and Society in Latin America A new map, ed. Cesar Rodriguez-Garavito, UK, Routledge, 2015.

H. Lindahl, Fault Lines of Globalization: Legal Order and the Politics of A-Legality, Oxford: Oxford University Press, 2013.

A. Philippopoulos-Mihalopoulos, "Law's Spatial Turn: Geography, Justice and a Certain Fear of Space", Law, Culture and the Humanities 7, no. 2, 2011, 187-202.

A. Philippopoulos-Mihalopoulos, Spatial Justice: Body, Lawscape, Atmosphere, UK, Routledge, 2015.

C. Philo, The Same and the Other': on geographies, madness and outsiders, Loughborough University of Technology, Department of Geography, Occasional Paper 11, 1986, 1-71, doi: http://eprints.gla.ac.uk/116553/1/116553.pdf.

S. Quiñones, "Tepito" in True Tales from another Mexico: The Lynch Mob, the Popsicle Kings, Chalino, and the Bronx, Albuquerque, University of New Mexico Press, 2001.

A. Schaap, et al. "Critical Exchange on 'Fault Lines of Globalization" in Contemporary Political Theory, 2015.

C. Schmid, "Henri Lefebvre's theory of the production of space: towards a three-dimensional dialectic", in Space, Difference, Everyday Life. Reading Henri Lefebvre, ed. Stefan Kipfer et al., UK/NY, Routledge, 2008.

E. Stuart. "There is a Politics of Space because Space is Political. Henri Lefebvre and the Production of Space". Radical Philosophy Review 10, no. 2, 2007.

The author, Marisela López Zaldívar, holds a master degree in Sociology of Law by the International Institute for the Sociology of Law. Research assistant, Art department, Faculty of Philosophy, Universidad Iberoamericana. E-mail: mar.lopez.zaldivar@gmail.com 